\title{
СООТНОШЕНИЕ ПРЕДЕЛОВ ДЕЙСТВИЯ МЕЖДУНАРОДНО-ПРАВОВОГО ЗАПРЕТА ПРИМЕНЕНИЯ СИЛЫ И ЗАЩИТЫ ГРАЖДАНСКОГО НАСЕЛЕНИЯ НА ПРИМЕРЕ ЙЕМЕНА
}

\begin{abstract}
Аннотация: Предметом исследования выступают теоретические и практические аспекты положения, прав и зашиты гражданского населения в условиях вооруженного конфликта (на примере Йемена). Особое внимание уделено взаимодействию региональных организаций и ООН в вопросе применения силь в международных отношениях и практическому применению ст. 51 Устава ООН. Постановка основной проблемы - это этика использования силь для оказания помощи гражданскому населению и необходимость ограничения средств, таких как авиаудары и другие средства с низкой точностью поражения. Методологическую основу составили такие научные методы познания, как сравнительно-правовой, исторический анализ, аналогия, индукция, дедукция и др. Сделан следующий вывод: единственно возможная защчита гражданского населения может быть обеспечена в рамках государства при условии создания работающего механизма привлечения к ответственности за серьезные нарушения норм международного гуманитарного права и прав человека как в мирное время, так и в условиях вооруженного конфликта.
\end{abstract}

Ключевые слова: Защчита, гражданское население, ООН, региональные организации, международные отношения, международное право, усстав ООН, самооборона, Йемен, вооруженный конфликт.

Abstract: The subject of this research is the theoretical and practical aspects of the position of rights and protection of civilian population during an armed conflict (on the example of Yemen). A special attention is given to the cooperation of regional organizations and the United Nations on the issue of use of force within international relations, and the practical application of Article 51 of the UN Charter. The postulation of the main problem is the ethics of use of force for the purpose of helping the civilian population, as well as the need to limit the means such as airstrikes and other means with low-precision destruction. The following conclusion is made: the only possible way to protect the civilian population can be ensured within the framework of a country through the creation of a working mechanism for holding parties accountable for serious violations of the norms of international humanitarian law and human rights during peace time, as well as during an armed conflict.

Keywords: UN Charter, international law, international relations, regional organizations, UN, civilian population, protection, self-defense, Yemen, armed conflict.

\section{Введение}

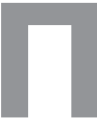
раво на жизнь является неотъемлемым естественным правом каждого человека. Это право является абсолютным и обеспечивается защитой со стороны государства, на территории которого находится человек, вне зависимости от того, является ли он гражданином данного государства или нет. Сегодня, количество перемещенных лиц в связи с конфликтами и насилием составляет около 38 миллионов человек и 13 миллионов человек живут на правах беженцев [1]. Актуальность вопроса соотнесения защиты гражданского населения и действий государства, либо группы государств, реализующих право на самооборону подтверждается реалиями сегодняшнего дня. В условиях конфликтов, имеющих место на территории Сирии и
Йемена, Ирака, в том числе, можно реально видеть, как сходятся вопросы терроризма, безопасности и нарушения как обычных, так и договорных норм международного гуманитарного права. В настоящей статье ставятся две задачи, одна из которых - осуществление правового анализа документов, положенных в основу решения использования права на индивидуальную и коллективную самооборону согласно статье 51 Устава ООН (на примере Йемена). Вторая задача - анализ норм, закрепляющих ответственность государства, вытекающую из принятых обязательств, принятых ими по международному гуманитарному праву. Поставленные задачи направлены на выявление посредством анализа реального положения меньшинств, в частности, этнических и религиозных групп, которые оказываются в основной группе риска в условиях вооруженного 
DOI: $10.7256 / 1811-9018.2015 .8 .15922$

При цитировании этой статьи сноска на доі обязательна

\section{Право и политика 8 (188) 2015}

конфликта [2]. Сложность конфликтов сегодняшнего дня отличается характером огромных потоков вынужденных переселенных лиц, беженцев, лиц, пытающихся скрыться от физической опасности, посягающей на неотъемлемое право на жизнь, здоровье, безопасность [3].

\section{Запрет использования силы и угрозы силой в международных отношениях.}

Сила в международных отношениях и даже угроза ее применения находятся под запретом, установленным согласием государств, выраженным в Уставе $\mathrm{OOH}$. Государства - члены ООН обязуются воздерживаться в их межгосударственных отношениях от угрозы силой или ее применения, это обязательство закреплено в п.4 статьи 2 Устава ООН [4]. Данное обязательство сформулировано в качестве принципа и закреплено в Декларации о принципах международного права, касающихся дружественных отношений и сотрудничества между государствами в соответствии с Уставом ООН от 24 октября 1970 г. [5]. Ранее был заключен общеизвестный пакт Бриана - Келлога 1928 г., который вошел в историю как договор, который осудил войну как средство разрешения международных конфликтов и отказ от применения силы в качестве орудия политики [6, с. 818]. Однако, в каждом конфликте фактически есть риск применения силы вопреки международно-правовому запрету, установленному в Уставе ООН. К сожалению, не всегда государствам удается самостоятельно урегулировать вопросы по наведению внутреннего конституционного порядка собственными силами. Это касается ситуаций, когда массовые внутренние беспорядки переходят в качество внутреннего вооруженного конфликта и влекут за собой серьезные нарушения норм международного гуманитарного права, ряда норм внутригосударственного права и международного права прав человека. Так, ситуация в Йемене и ряде других государств подтверждает, что государства, являясь субъектами международного права, реализуя свою внешнюю политику в соответствии с собственными национальными интересами, принимают решения о применении вооруженных сил в целях установления регионального порядка и борьбы с терроризмом [7]. В данном случае, сила была применена не на основании резолюции Совета Безопасности ООН. Решение о применении силы было принято региональной организацией на основании обращения главы государства со ссылкой на статью 51 Устава ООН, с просьбой «оказать любую возможную поддержку и принять необходимые меры, включая военное вмешательство» [8]. Совет
Безопасности ООН позднее был проинформирован о принятии решения и проведении операции. В деле, касающемся военных и военного характера действий в Никарагуа и против Никарагуа (Никарагуа против США) Международный суд ООН отметил, что право на самооборону является «исключением» из принципа запрещения применения силы в международных отношениях [9, p. 92]. Необходимо трактовать главу 7 Устава ООН в узком смысле. Сила может быть применена в международных отношениях только на основании резолюции Совета Безопасности ООН-главного ответственного органа за соблюдение мира и безопасности в мире. Никакого расширительного толкования статьи 51 Устава ООН быть не должно. Статья 51 Устава ООН содержит положение и признает «существование неотъемлемого права на самооборону в случае вооруженного нападения одного государства на другое», что подтверждается в решении Международного суда $\mathrm{OOH}[10$, c. 58]. Также, согласно статьи 53 Устава ООН, «Совет Безопасности использует, где это уместно, такие региональные соглашения или органы для принудительных действий под его руководством», при этом «никакие принудительные действия не предпринимаются, в силу этих региональных соглашений или региональными органами, без полномочий от Совета Безопасности ООН» [11]. Совет Безопасности должен быть всегда полностью информирован о действиях, предпринятых или намечаемых в силу региональных соглашений или региональными органами для поддержания международного мира и безопасности согласно статьи 54 Устава ООН.

Крайне важно соблюдение сторонами вооруженного противостояния норм и правил в отношении гражданского населения, всех категорий жертв согласно Женевскому праву. Вооруженный конфликт немеждународного характера определяют как вооруженное противостояние, имеющее место в пределах территории государства между правительством и вооруженными группами и лицами, входящими «в состав таких групп назовем ли мы их повстанцами, мятежниками, революционерами, сепаратистами, борцами за свободу, террористами или каким-либо другим именем, - сражаются с целью захвата власти, или за достижение большей автономии в пределах государства, или за отделение и создание собственного государства» [12, с. 92]. В правовом смысле, нельзя отождествлять террористов с народами, борющимися за самоопределение, так как цели одних и других могут существенно отличаться. Другой вопрос, в том, чтобы народы, борющиеся за самоопределение не использовали террористические 
DOI: $10.7256 / 1811-9018.2015 .8 .15922$

При цитировании этой статьи сноска на dоі обязательна

Международное право в XXI веке

методы в своей борьбе, в частности такие террористические средства, как использование смертников, начиненные взрывчатыми устройствами автомобили, приводимые в действие в местах скопления людей. В рамках Женевских конвенций отсутствует определение «терроризма», так же, как и в целом в гуманитарном праве [13, р. 28]. По сути, разница заключается в определении наказания за действия того или иного характера. При нарушении норм международного гуманитарного права, нарушители привлекаются к ответственности за военные преступления в пределах государства, под чьей юрисдикцией они находятся, либо «передавать их для предания суду другому заинтересованному государству в том случае, если это государство имеет доказательства, дающие основание для обвинения этих лиц» [14]. В случае террористической деятельности, согласно принципу универсальной юрисдикции, лица могут быть привлечены к уголовной ответственности любым государством без привязки к территории государства, в котором был произведен террористический акт [15]. Так, резолюция СБООН S/RES/1624 (2005) осуждает решительным образом «все акты терроризма, независимо от их мотивации, места осуществления и исполнителей, как одну из самых серьезных угроз миру и безопасности» [16]. Тем не менее сложившаяся система международного права строго ограничивает применение силы и позволяет применять последнюю, только на основании Главы VII Устава ООН.

По смыслу статьи 8 Статута МУС «f) Пункт 2(e) применяется к вооруженным конфликтам немеждународного характера и, таким образом, не применяется к случаям нарушения внутреннего порядка и возникновения напряженности, таким, как беспорядки, отдельные и спорадические акты насилия или иные акты аналогичного характера. Он применяется в отношении вооруженных конфликтов, которые имеют место на территории государства, когда идет длительный вооруженный конфликт между правительственными властями и организованными вооруженными группами или между самими такими группами» [17]. Конфликт в Сирии вполне отвечает все критериям, заложенным в данной статье. Однако, Сирия как и Йемен не ратифицировали Статут МУС.

Когда мы говорим о применении норм международного права, предполагается выбор режима норм конкретных международных договоров, таких как Женевские конвенции и, в частности, статья 3 Общая для всех Женевских конвенций 1949 г., а также Дополнительный протокол II 1977 г. к ним. Пороговые требования являются основными составляющими для определения вооруженного конфликта в качестве такового. Соответственно, если ситуация не отвечает пороговым критериям, то вооруженного конфликта немеждународного характера нет и нормы международного гуманитарного права применены быть не могут. Каким образом квалифицировать конфликт: как международный, либо как вооруженный внутренний конфликт немеждународного характера, как интернационализированный осложняет не только выбор тех или иных правовых средств, но и мешает формированию единой политической позиции мирового сообщества по отношению к выбору средств урегулирования конфликта. Определение интернационализированного конфликта выражено в определении: «интернационализированный вооруженный конфликт - означает войну между двумя внутренними группировками, каждую из которых поддерживают разные государства; прямые военные действия между двумя иностранными государствами, осуществляющими военное вмешательство во внутренний вооруженный конфликт в поддержку противостоящих друг другу сторон, и войну с иностранным вмешательством в поддержку повстанческой группировки, воюющей против существующего правительства» [18, p. 255]. В деле «Обвинитель против Душко Тадича» установлено, что «...вооруженный конфликт существует тогда, когда имеет место применение вооруженной силы между государствами или в течение длительного периода совершаются вооруженные акты насилия между государственными властями и организованными вооруженными группами или между такими группами внутри государства» [19]. Если исходить из такого определения, ситуация в Йемене, Сирии может быть четко определена как вооруженный конфликт, потому что как в одной, так и в другой стране имеют место вооруженные длительные столкновения вооруженных групп с государственными властями.

Государства не могут давать согласие на нарушение своих обязательств по международному гуманитарному праву или международному праву прав человека. Государство, дающее согласие на деятельность другого государства на своей территории, в любом случае и «по-прежнему несет ответственность за выполнение своих обязательств в области прав человека, включая обеспечение соблюдения прав человека и, следовательно, предотвращение нарушений права на жизнь настолько, насколько оно способно это сделать» [20].

Взаимодействие ООН и региональной организации можно увидеть, в частности, через взаимодействие 
DOI: $10.7256 / 1811-9018.2015 .8 .15922$

При цитировании этой статьи сноска на доі обязательна

\section{Право и политика 8 (188) • 2015}

Генерального секретаря ООН с Генеральным секретарем региональной организации - Лиги арабских государств, представителями таких государств Китай, Россия, Соединенное Королевство, США, Франция, Турция, Ирак (Председатель Саммита Лиги арабских государств), Кувейт (Председатель Совета министров Лиги арабских государств) и Катара (Председатель Арабского комитета по наблюдению за ситуацией в Сирии Лиги арабских государств), а также Высоким представителем по иностранным делам и политике безопасности Европейского союза в составе Группы действий по Сирии [21]. Устав Совета сотрудничества арабских государств не содержит положений относительно вопроса о поддержании регионального мира и безопасности [22].

Религиозный аспект конфликта, выраженный в противостоянии сторон, принадлежащих к разным течениям исламской религии, что не может не влиять на оценку и восприятие его остальными странами региона с преимущественно мусульманским населением, относящим себя к тому или иному религиозному направлению. Так, не могут быть индифферентными такие государства как Ирак и другие страны региона.

Уважение суверенитета государств выражается в признании факта, что государства в рамках своей территории осуществляет свою внутреннюю политику и, соответственно, «государства несут главную ответственность за соблюдение и обеспечение прав человека своих граждан, а также лиц, находящихся на их территории, как это предусмотрено соответствующими нормами» [23].

Например, мера, принимаемая международным сообществом в целях содействия обеспечению выполнения норм международного гуманитарного права в практике государств, выражена, во включении в качестве дополнительного критерия в санкционный перечень, установленный резолюцией Совета Безопасности ООН 2140(2014) от 26 февраля 2014 г.: «препятствование доставке гуманитарной помощи Йемену или доступу к гуманитарной помощи или ее распределению в Йемене» [24].
Важно отметить, что взаимодействие $\mathrm{OOH}$ с региональными организациями в деле предотвращения и урегулирования конфликтов происходит посредством непосредственного принятия решений и рекомендаций. Так, например, ГА ООН предложила Генеральному секретарю $\mathrm{OOH}$ «в соответствии с его кругом ведения оказать поддержку миссии наблюдателей Лиги арабских государств в Сирийской арабской республике, при поступлении соответствующей просьбы» [25].

О противоречиях во взгляде на эффективность авиаударов для гуманитарных целей пишут многие авторы [26, с. 597]. Во время неизбирательных авиаударов гибнут мирные жители. Так, в Йемене была «разрушена гражданская инфраструктура, поскольку в населенных районах часто совершались авиаудары» [27]. Авиационные бомбы - это оружие неизбирательного действия, поэтому применение этого вида оружия должно быть строго ограничено. Государства - члены ООН должны взять на себя «обязательство в связи с воздержанием применения взрывного действия с большой зоной поражения в населенных районах» [28].

\section{Вывод:}

Таким образом, единственно возможная защита гражданского населения может быть обеспечена в рамках государства при условии создания работающего механизма привлечения к ответственности за серьезные нарушения норм международного гуманитарного права и права прав человека, как в мирное, так и в условиях вооруженного конфликта. При принятии решения о проведении любых действий в рамках реализации права на индивидуальную или коллективную самооборону согласно статьи 51 Устава $\mathrm{OOH}$, такие действия должны быть предприняты исключительно в соответствии со строгим пониманием запрета применения силы в международных отношениях. Защита гражданского населения должна быть приоритетной задачей каждого государства, так как народ является государствообразующим и самым важным составляющим современного правового государства.

\section{Библиография:}

1. Доклад Генерального секретаря по вопросу о защите гражданских лиц в вооруженном конфликте, S/2015/453, от 18 июня 2015 г. http://www.un.org/ga/search/view_doc.asp?symbol=S/2015/453\&Lang=R

2. Letter dated 12.03.2015 from the Charge d'Affaires a.i. of the Permanent Mission of France the the UN addressed to the Secretary General. S/2015/176. URL:http:/www.securitycouncilreport.org/atf/cf/\%7B65BFCF9B-6D27-4E9C-8CD3CF6E4FF96FF9\%7D/s_2015_176.pdf

3. http://www.unhcr.org.uk/fileadmin/user_upload/pdf/Jan2015_Displacement_Facts_and_Figures_incMYT2014.pdf

4. http://www.un.org/ru/documents/charter/chapterl.shtml 
DOI: $10.7256 / 1811-9018.2015 .8 .15922$

При цитировании этой статьи сноска на dоі обязательна

Международное право в XXI веке

5. http://www.un.org/ru/documents/decl_conv/declarations/intlaw_principles.shtml

6. Вольфганг граф Витцтум и др. Международное право, Берлин, 2007, С.818.

7. Identical letters dated 26 of March 2015 from the Permanent Representative of Qatar to the United Nations addressed to the Secretary-General and the President of the Security Council , S/2015/217 URL:http:/www.securitycouncilreport.org/atf/ cf/\%7B65BFCF9B-6D27-4E9C-8CD3-CF6E4FF96FF9\%7D/s_2015_217.pdf

8. Резолюция S/RES/2216 (2015) СБ ООН от 14 апреля 2015 г. http://daccess-dds-ny.un.org/doc/UNDOC/GEN/N15/103/75/PDF/ N1510375.pdf?OpenElement

9. Case concerning military and paramilitary activities in and against Nicaragua (Nicaragua v.USA), Judgment of 27 of June 1986, paragraph 193, page. 92 (URL:http://www.icj-cij.org/docket/files/70/6503.pdf)

10. Консультативное заключение Международного суда относительно правовых последствий строительства стены на оккупированной палестинской территории, A/ES-10/273., от 13 июля 2004г., C.58,URL: http://www.icj-cij.org/homepage/ru/ advisory/advisory_2004-07-09.pdf

11. http://www.un.org/ru/documents/charter/chapter8.shtml

12. Ханс-Петер Гассер «Международное гуманитарное право. Введение», МККК, М.:1995, С.92/

13. Marco Sassoli, Antoine A.Bouvier, Anne Quintuin, "How does Law protect in war? Cases, Documents and teaching materials on Contemporary Practice in International Humanitarian Law", Volume I, ICRC Third Edition, p.28.

14. Резолюция S/RES/2222 (2015) СБ ООН от 27 мая 2015 г. URL:http://daccess-dds-ny.un.org/doc/UNDOC/GEN/N15/153/83/ PDF/N1515383.pdf?OpenElement

15. Пункт b статьи 5 Декларации о мерах по ликвидации международного терроризма, принятая резолюцией ГАООН №. 49/60 от 09.12.1994г., URL:http://www.un.org/ru/documents/decl_conv/declarations/terrdec1.shtml

16. http://daccess-dds-ny.un.org/doc/UNDOC/GEN/N05/510/54/PDF/N0551054.pdf?OpenElement

17. http://www.un.org/ru/law/icc/rome_statute $\% 28 \mathrm{r} \% 29 . \mathrm{pdf}$

18. D. Schindler, "International Humanitarian Law and internationalized internal armed conflicts", International Review of the Red Cross, N.230,1982, p.255.

19. Международный уголовный трибунал по бывшей Югославии, дело № IT-94-1-A72, Prosecutor v. Duško Tadića/k/a “DULE”, Appeals Chamber, 2 October 1995, para. 70 (1994-1995), 1 ICTY JR 352, para. 70.

20. Проект статей об ответственности государств за международно-противоправные деяния, статья 23, Ежегодник Комиссии международного права, 2001 год, том II, часть 2.

21. Заключительное коммюнике «Группы действий» по Сирии, Женева, 30 июня 2012 года (1282-01-07-2012).

22. http:/www.chemico-group.com/ru/images/stories/docs/ustav.pdf

23. Резолюция S/Res/ 2222 (2015) СБ ООН от 27.05.2015 г. URL:http://daccess-dds-ny.un.org/doc/UNDOC/GEN/N15/153/83/PDF/ N1515383.pdf?OpenElement

24. Резолюция S/Res/ 2216 (2015) СБООН от 14.04.2015 г. URL:http://daccess-dds-ny.un.org/doc/UNDOC/GEN/N15/103/75/PDF/ N1510375.pdf?OpenElement

25. Резолюция ГА ООН A/RES/66/176 от 19.12.2011 г. URL:http://daccess-dds-ny.un.org/doc/UNDOC/GEN/N11/469/40/PDF/ N1146940.pdf?OpenElement

26. International Law (3d edn) [edited by] M.Evans. Oxford University Press, 2010, C.597.

27. Доклад Генерального секретаря по вопросу о защите гражданских лиц в вооруженном конфликте, S/2015/453 от 18 июня 2015 г.

28. Доклад Генерального секретаря по вопросу о защите гражданских лиц в вооруженном конфликте, S/2015/453 от 18 июня 2015 г. C.22/24. URL:http://www.un.org/ga/search/view_doc.asp?symbol=S/2015/453\&Lang=

\section{References (transliterated):}

1. Vol'fgang graf Vittstum i dr. Mezhdunarodnoe pravo, Berlin, 2007, S.818.

2. Khans-Peter Gasser «Mezhdunarodnoe gumanitarnoe pravo. Vvedenie», MKKK, M.:1995, S.92/

3. Marco Sassoli, Antoine A.Bouvier, Anne Quintuin, "How does Law protect in war? Cases, Documents and teaching materials on Contemporary Practice in International Humanitarian Law", Volume I, ICRC Third Edition, p.28.

4. D.Schindler, "International Humanitarian Law and internationalized internal armed conflicts", International Review of the Red Cross, N.230,1982, p.255. 